\title{
Self-Reported Wisdom and Happiness: An Empirical Investigation
}

\author{
Ad Bergsma $\cdot$ Monika Ardelt
}

Published online: 27 May 2011

(C) The Author(s) 2011. This article is published with open access at Springerlink.com

\begin{abstract}
Possible tensions between wisdom and happiness have been extensively debated in philosophy. Some regard wisdom as the 'supreme part of happiness', whereas other think that a more accurate and wiser view on reality might reduce happiness. Analyzing a Dutch internet survey of 7037 respondents, we discovered that wisdom and happiness were modestly positively related. Wisdom, measured with the Three-Dimensional Wisdom Scale (3D-WS), explained 9.2\% of the variation in hedonic happiness. The correlation with the reflective dimension of wisdom was the strongest. In addition, wisdom was more important for happiness among adults with only an elementary education. Our results suggest that happiness and wisdom do not conflict.
\end{abstract}

Keywords Happiness - Wisdom - Utilitarianism - Eudaimonic well-being · Positive affect $\cdot$ Personal growth $\cdot$ Adjustment

The thought that the enjoyment of reality is good in itself is already embodied in the wisdom of the Talmud; it states that everybody has to justify himself in the life hereafter for every failure to enjoy a legitimately offered pleasure in this world.

Marie Jahoda (1958)

The most manifest sign of wisdom is a continual cheerfulness: her state is like that of things in the regions above the moon, always clear and serene.

Michel de Montaigne (1905)

\footnotetext{
A. Bergsma $(\bowtie)$

Faculty of Social Sciences, Erasmus University Rotterdam, P.O. Box 1738, 3000 DR Rotterdam, The Netherlands

e-mail: bergsma@fsw.eur.nl

M. Ardelt

Department of Sociology and Criminology \& Law, University of Florida, P.O. Box 117330, Gainesville, FL 32611-7330, USA

e-mail: ardelt@ufl.edu
} 
We seek happiness for the sake of itself, but we choose virtues such as honour and reason not only for their sakes, but also for the sake of happiness. Aristotle (350 B.C.E.) wrote these famous words in his Nicomachean Ethics. He concluded that happiness is the ultimate goal. Yet, his concept of happiness is not strictly hedonic. It has clear elements of eudaimonic well-being (Franklin 2010). For Aristotle, happiness is acting virtuously and feeling good because of that (Ryan and Deci 2001).

Bentham (1789 [1970]) took Aristotle's idea about the ultimate goal and gave it a psychological twist by using a restricted definition of happiness as the sum of pleasures minus pains. His moral philosophy is based on the idea that we should seek the greatest hedonic happiness for the greatest number of people. This idea has remained influential. For example, the modern scholar Tal Ben-Shahar (2007) refers to happiness as the ultimate currency, and reasoning about ultimate happiness is gaining momentum in society. Several sociologists, economists, and politicians state that traditional socioeconomic indicators such as Gross Domestic Product (GDP) are measuring means rather than ends. By contrast, Gross National Happiness is used as a goal for development in Bhutan (Priesner 1999). In the West, the same idea is propagated by noted scholars, such as Kahneman et al. (1997) and Layard (2005), who argue that the promotion of happiness could be used to guide government decisions.

Although this line of reasoning has gained prominence in the last decade (Veenhoven 2004), the idea about an ultimate currency is still under debate. A major objection is that hedonic happiness is not sufficient to assess whether people are faring well (Ryff 1989). One issue in the debate is whether growing wiser is more desirable than being happy and whether the attainment of wisdom might be accompanied by distress (Staudinger and Glück 2011; Staudinger and Kunzmann 2005). We approach this issue empirically by assessing both happiness and wisdom in a Dutch internet survey of 7037 respondents.

We start with a discussion of the elusive constructs of happiness and wisdom, followed by a short philosophical exposé of the presumed relation between happiness and wisdom and how these concepts fit into the recent psychological debate about the relative importance of eudaimonic and hedonic well-being. We then summarize earlier empirical research on the association between wisdom and happiness before we present our own findings.

\section{Defining Happiness}

In a broad sense, the word happiness is used for 'quality of life' or 'well-being', denoting that life is good but without specifying what is good about life. Veenhoven (2004) has charted the different meanings conveyed by the term, using a classification scheme of four qualities of life (see Table 1). This classification is based on two distinctions: Vertically there is a difference between opportunities for a good life and actual outcomes of life. The distinction is important, because people can fail to use the life chances offered to them. The horizontal distinction refers to external qualities of the environment and internal qualities of the individual. Together, these two dichotomies produce four qualities of life, which have all been denoted by the word 'happiness'.

The upper left quadrant (livability of the environment) represents good living conditions, such as material affluence, schooling, political freedom, and social equality, which raise the chances of people feeling good about their lives The upper right quadrant (lifeability of the person) denotes how well an individual is able to seize opportunities and to cope with the problems of life. Good life-ability gives individuals the possibility to make 
Table 1 Four qualities of life

\begin{tabular}{lll}
\hline & External life qualities & Internal life qualities \\
\hline Life Chances & Livability of environment & $\begin{array}{l}\text { Life-ability of the person } \\
\text { Life Results }\end{array}$ \\
\hline
\end{tabular}

the best of different circumstances. The bottom left quadrant (utility of life) represents the notion that a good life must serve some higher function, such as ecological preservation, virtue, or cultural development. Gerson (1976, p. 795) referred to this variant as 'transcendental' conceptions of quality of life. The combination of life-ability of the person and the utility of life is similar to Ryff's (1989; Ryff and Keyes 1995) concept of psychological well-being, which consists of environmental mastery, autonomy, self-acceptance, positive relations with others, personal growth, and purpose in life. Finally, the bottom right quadrant (denoted by satisfaction with life) describes the internal appreciation of one's life. This latter definition is most closely associated to Bentham's (1789 [1970]) view of happiness as the sum of pleasures minus pains, although we realize that there is a difference between life satisfaction and happiness. If happiness is affected by daily pleasures and pains, it is likely that it is less stable than an overall feeling of satisfaction with life, which is based on comparisons between past aspirations and present achievements (Fisher 1992; George and Bearon 1980).

In this paper, we follow Bentham's definition of happiness as the affective appreciation of one's life. We measured happiness with self-reports and asked participants to rate how happy they have felt in the last 3 months and today.

\section{Defining Wisdom}

Although wisdom is a complex concept and difficult to define (Sternberg 1990; Sternberg and Jordan 2005), historically it has been considered the pinnacle of human development (Baltes and Staudinger 2000). For example, Kunzmann (2004, p. 504) described wisdom as '... a perfect, perhaps utopian, integration of knowledge and character, of mind and virtue.' Wise people presumably possess many positive qualities, such as a mature and integrated personality, superior judgment skills in difficult life matters, and the ability to cope with the vicissitudes of life (e.g., Ardelt 2004).

Unfortunately, even after three decades of contemporary wisdom research, a generally agreed upon definition of this elusive concept does not exist. Meeks and Jeste (2009) analyzed 10 major definitions and descriptions of wisdom and found that six subcomponents were included in at least three of these definitions: (1) prosocial attitudes/behaviors, (2) social decision making/pragmatic knowledge of life, (3) emotional homeostasis, (4) reflection/self-understanding, (5) value relativism/tolerance and (6) acknowledgement of and dealing with uncertainty/ambiguity. In this study, we define and operationalize wisdom as an integration of cognitive, reflective, and compassionate personality characteristics. Our measure is based on prior research by Clayton and Birren (1980) and further developed by Ardelt (1997, 2003, 2004). This general, yet relatively parsimonious description of wisdom seems to be compatible with most of the definitions found in the ancient and contemporary wisdom literature (Ardelt 2011b; Ardelt and Oh 2010; Manheimer 1992) and is also distinct enough to distinguish a wise person from, for example, an intelligent, creative, or altruistic individual (Ardelt 2004). 
As summarized in Table 2, the cognitive dimension of wisdom refers to the desire to know the truth. This does not only imply a knowledge of facts but also a deep understanding of life, particularly with regard to intrapersonal and interpersonal matters, including knowledge and acceptance of the positive and negative aspects of human nature, of the inherent limits of knowledge, and of life's unpredictability and uncertainties (Ardelt 2000; Brugman 2000; Kekes 1983). A deep and undistorted comprehension of reality can only be achieved by overcoming one's subjectivity and projections through the practice of (self-)reflection (Kekes 1995). The reflective dimension of wisdom highlights this aspect and represents the ability and willingness to invest in self-examination, self-awareness and self-insight. It requires the perception of phenomena and events from different perspectives and the ability to 'see through illusions' (McKee and Barber 1999). According to Kramer (1990, p. 296), 'one must be able to first become aware of and then transcend one's projections before one can develop both the empathic skills and the cognitive processes associated with wisdom'. Reflectivity tends to reduce self-centeredness, which leads to a deeper understanding of one's own and others' motives and behavior, and is likely to result in greater sympathetic and compassionate love for others. All-encompassing sympathetic and compassionate love accompanied by a motivation to foster the well-being of all denotes the compassionate component of wisdom (Achenbaum and Orwoll 1991; Csikszentmihalyi and Rathunde 1990; Levitt 1999; Staudinger and Glück 2011).

It should be noted that this definition of wisdom does not imply that wise individuals will avoid or suppress negative emotions toward themselves or others if they arise. On the contrary, through self-awareness and self-examination (the reflective wisdom dimension) wise persons are able to acknowledge, regulate, and ultimately overcome their negative

Table 2 Definition and operationalization of wisdom as a three-dimensional personality characteristic

\begin{tabular}{|c|c|c|}
\hline Dimension & Definition & Operationalization \\
\hline Cognitive & $\begin{array}{l}\text { An understanding of life and a desire to } \\
\text { know the truth, i.e., to comprehend the } \\
\text { significance and deeper meaning of } \\
\text { phenomena and events, particularly with } \\
\text { regard to intra- and interpersonal matters } \\
\text { Includes knowledge and acceptance of the } \\
\text { positive and negative aspects of human } \\
\text { nature, of the inherent limits of } \\
\text { knowledge, and of life's unpredictability } \\
\text { and uncertainties }\end{array}$ & $\begin{array}{l}\text { Items or ratings assess } \\
\text { the ability and willingness to understand a } \\
\text { situation or phenomenon thoroughly; } \\
\text { knowledge of the positive and negative } \\
\text { aspects of human nature; } \\
\text { acknowledgement of ambiguity and } \\
\text { uncertainty in life; } \\
\text { the ability to make important decisions } \\
\text { despite life's unpredictability and } \\
\text { uncertainties }\end{array}$ \\
\hline Reflective & $\begin{array}{l}\text { A perception of phenomena and events from } \\
\text { multiple perspectives } \\
\text { Requires self-examination, self-awareness, } \\
\text { and self-insight }\end{array}$ & $\begin{array}{l}\text { Items or ratings assess } \\
\text { the ability and willingness to look at } \\
\text { phenomena and events from different } \\
\text { perspectives; } \\
\text { the absence of subjectivity and projections } \\
\text { (i.e., the tendency to blame other people or } \\
\text { circumstances for one's own situation or } \\
\text { feelings) }\end{array}$ \\
\hline Compassionate & $\begin{array}{l}\text { All-encompassing sympathetic and } \\
\text { compassionate love accompanied by a } \\
\text { motivation to foster the well-being of all } \\
\text { Requires the transcendence of self- } \\
\text { centeredness }\end{array}$ & $\begin{array}{l}\text { Items or ratings assess } \\
\text { the presence of positive, caring, and } \\
\text { nurturant emotions and behavior toward } \\
\text { others; } \\
\text { the absence of indifferent or negative } \\
\text { emotions and behavior toward others }\end{array}$ \\
\hline
\end{tabular}

Adapted from Ardelt (2004) 
emotions and projections without adversely affecting their own lives and that of others (Webster 2003). For example, the practice of mindfulness and mindfulness meditation appear to facilitate the acceptance and eventual transcendence of negative emotions and behavior (Barbieri 1997; Farb et al. 2010; Kabat-Zinn 2003; Speca et al. 2000). As defined in the present study, wisdom has a utopian quality, but it should be possible to assess how close people come to this ideal state (Ardelt 2004).

\section{Wisdom and Happiness in Philosophy}

It is not hard to find supporters of the idea that wisdom is important for happiness in the history of philosophy. Thomas Aquinas (1923, p. 3) wrote, 'Of all human pursuits, that of wisdom is the most perfect, the most sublime, the most profitable, the most delightful.' The profession of philosophical counseling, which uses philosophical means for treating everyday problems and predicaments, is partly based on this idea. Marinoff (2003) argued that philosophizing about life helps people to develop the practical wisdom that enables them to deal with life more efficiently. His motto is the following quote by Epicure: 'Vain is the word of the philosopher which does not heal any suffering of man. For just as there is no profit in medicine if it does not expel the diseases of the body, there is no profit in philosophy either if it does not expel the suffering of the mind.'

Still, the idea that wisdom leads to happiness is controversial. We can feel better without growing in wisdom, as exemplified by the use of psychotropic medication and behavioral therapy that employs basic learning mechanisms. Moreover, Amir (2004) stated that studying philosophy sometimes leads to confusion or discouragement and that the search for wisdom through philosophical counseling might contribute to unhappiness. It can be very frustrating to acquire a better understanding of one's predicament if one does not have the means to resolve it. Hence, wisdom or greater insight might harm happiness.

In philosophy, wisdom is not only seen as a life-ability that might enhance happiness, but as a goal in itself and as such, wisdom might conflict with happiness by, first, increasing one's insight into life and, second, through the realization that other things might be more important than the pursuit of happiness. To illustrate the first downside of wisdom, Feldman (2008, p. 231) used the example of 'Timmy' who is always cheerful with all the happiness neurotransmitters flowing around in his brain. He never thinks about a life goal, however, and when he is prompted to review his life in this light he 'promptly becomes despondent and would judge his life as a whole to have been worthless'. A grain of wisdom has made Timmy unhappy. This possibility is summed up by the popular expression 'sadder but wiser'. Happiness appears to profit from embracing (unwise) positive illusions about the relative superiority of ourselves (Headey and Wearing 1992). Without positive illusions, we run an elevated risk for depression. The phenomenon called depressive realism describes the tendency of mildly depressed people to view themselves and the world realistically (Collijn 1991).

Second, if wisdom encourages us to transcend our self-interests, we might choose options in life that are detrimental to happiness. According to Buss (2004), sometimes it is wiser to resist oppression and to do what is right, even if it involves sacrificing our happiness, than to go along with a harmful social system. For example, Mohr (1992) argued that dignity for homosexuals takes preference over their feelings of happiness and that coming out is a form of 'community duty' that might help improve the position of homosexuals in the long run. These philosophers deem it wise to sacrifice individual happiness for the sake of the greater good. Yet, paradoxically, the pursuit of altruistic and 
virtuous goals might ultimately lead to greater and longer lasting happiness than the direct pursuit of sensory pleasures (Ryan and Deci 2001).

\section{Personal Adjustment Versus Growth}

Psychologists distinguish between hedonic or subjective well-being, such as happiness, and eudaimonic or psychological well-being, which refers to the actualization of human potentials, such as growth in wisdom (Ryan and Deci 2001; Ryff 1989; Waterman 1993). According to Staudinger and Kunzmann (2005), personal adjustment, described as positive developmental changes that have adaptive value for the individual as well as the community, is likely accompanied by subjective well-being. Adjustment entails 'that we become self-assured and self-protected, which help us to avert "damage" form our view of the world and ourselves' (p. 326). Yet, personal growth and wisdom transcend the given societal circumstances and go beyond integration in social structures and the maintenance of subjective well-being. Growth is characterized by 'increases in virtues such as insight, integrity, self-transcendence, and the striving towards wisdom' (p. 321). The attainment of wisdom, in turn, requires critical self-examination, flexibility, tolerance of ambiguity, and 'extraordinary effort and most likely pain' (p. 326). Moreover, sometimes adverse life circumstances foster the development of wisdom (Ardelt 1998; Ardelt et al. 2010). This does not imply, however, that wisdom is inversely related to happiness, although the path to wisdom might necessitate hard work, self-discipline, and endurance (Pascual-Leone 2000). For example, for Erikson (1982), wisdom is the virtue that results after the resolution of the psychosocial crisis of ego integrity versus despair in old age. Wise people know how to cope with crises and hardships in life and to sustain their emotional wellbeing even in difficult circumstances (Ardelt 1997, 2005). Also, assuming that a certain degree of personal adjustment is necessary to develop wisdom (Staudinger and Kunzmann 2005), wise persons will have a higher starting point of happiness than individuals who have difficulties adjusting to life.

If it is true, as many wisdom researchers have argued, that wise individuals know "the art of living" or how to live a life that is good for oneself, good for others, and good for the whole society (Baltes and Staudinger 2000; Csikszentmihalyi and Nakamura 2005; Kekes 1995; Kramer 2000; Kupperman 2005; Sternberg 1998), they should also be content and satisfied with a life that is well lived (Ardelt 2000; Bianchi 1994; Clayton 1982; Vaillant 2002). In fact, Csikszentmihalyi and Nakamura (2005) argued that the pursuit and attainment of wisdom might be intrinsically rewarding and joyful due to the transcendence of one's self-centeredness. Happiness is not a zero sum game, and one of the best ways to become happy appears to be by contributing to the happiness of others (Headey and Wearing 1992).

Wisdom might also be necessary to make happiness sustainable (Bergsma 2000). Kraut (cited in Averill and More 1993) offers the following thought experiment to illustrate this point. Imagine you are still in high school and voted the most popular student by your peers. You are elated because of this well-deserved recognition, but afterwards you discover it was a cruel hoax: in reality you are the laughing stock of the school. The happiness you felt on the evening of the election is not something to think back of with gratitude. We want to be happy, but we need wisdom to shield us against painful illusions. In fact, happiness without wisdom might be short-sighted. In Bright-sided: How the relentless promotion of positive thinking has undermined America, Barbara Ehrenreich (2009) argued 
that being wiser and more in contact with reality might be hard at times but on average would make everybody happier in the long run.

\section{Empirical Research on the Association Between Wisdom and Happiness}

To our knowledge, only two studies have examined the relation between wisdom and happiness per se, although a number of studies have analyzed the association between wisdom and measures of subjective well-being, such as life satisfaction. The empirical evidence is mixed, with some studies finding a positive association between measures of wisdom and well-being and others failing to do so.

In a sample of 158 Canadian undergraduates, self-transcendent wisdom (Levenson et al. 2005) was positively related to the Subjective Happiness Scale (Lyubomirsky and Lepper 1999), even after controlling for self-actualization (Beaumont 2009). Similarly, in a sample of 177 undergraduate students from the United States, the reflective and compassionate components of Ardelt's (2003) Three-Dimensional Wisdom Scale (3DWS) correlated directly with the Subjective Happiness Scale and inversely with negative affect, although the cognitive dimension of the 3D-WS was uncorrelated with both scales (Neff et al. 2007).

In addition to happiness, wisdom has been found to be positively associated with measures of subjective well-being. For example, in a sample consisting of Jewish Canadian and Muslim Pakistani children, adolescents, and adults, higher wisdom, assessed by the 3D-WS and the Foundational Value Scale (Jason et al. 2001; Perry et al. 2002), was significantly related to greater life satisfaction (Ferrari et al. 2011). Similarly, in studies of economically diverse community samples of primarily older White adults $(M=64$ years $)$ and White and African American older adults ( $M=71$ years), the 3D-WS was positively correlated with life satisfaction (Le 2011) and general well-being and negatively related to depressive symptoms (Ardelt 2003). In an educational diverse sample of White older women $(M=68$ years $)$ and men ( $M=70$ years), wisdom, measured as a combination of cognitive, reflective, and compassionate personality characteristics from the California Q-Sort and Haan's (1969) Ego Rating Scale, had a stronger statistical effect on life satisfaction than objective indicators of quality of life, such as physical health, socioeconomic status, financial situation, physical environment, and social involvement (Ardelt 1997).

In a sample of middle-aged (36-59 years; $M=45$ years) and older (age $>65$; $M=70$ years) American and Japanese adults, both the reflective and compassionate synthetic wisdom mode and the cognitive analytical wisdom mode were positively associated with life satisfaction (Takahashi and Overton 2002). General wisdom-related knowledge, measured by the Berlin Wisdom Paradigm (e.g., Baltes et al. 1995) was also positively correlated with life satisfaction in a German sample of relatively highly educated younger adults ( $M=30$ years) and older adults $(M=67$ years), whereas personal wisdom, assessed as self-knowledge, growth and self-regulation, interrelating the self, selfrelativism, and tolerance of ambiguity, was unrelated to life satisfaction (Mickler and Staudinger 2008). Yet, in a different study by Kunzmann and Baltes (2003) with an educational diverse German sample ranging in age from 15 to 70 years, general wisdomrelated knowledge was inversely correlated with both positive/pleasant affect (e.g., exuberant, happy, proud) and negative affect (e.g., angry, afraid, ashamed). Although wise individuals might be more likely to be happy, they might be less likely to be exuberant or 
proud due to emotion regulation (Webster 2003) and the transcendence of the self (Csikszentmihalyi and Nakamura 2005).

Brugman (2000) who operationalized wisdom as expertise in uncertainty measured by the Epistemic Cognition Questionnaire (ECQ15) also obtained contradictory results. In a sample of highly educated older adults in the Netherlands $(M=74$ years), wisdom was unrelated to life satisfaction, but the ECQ15 correlated with life satisfaction in an educational diverse sample of middle-aged ( $M=50$ years) and older ( $M=83$ years) Dutch participants (Brugman 2000). Finally, in a sample of college-educated adults around the age of 52, neither practical wisdom (assessed by cognitive, reflective, and mature adjectives from the Adjective Check List) nor transcendent wisdom (ratings of respondents' examples of their own wisdom) was significantly correlated with life satisfaction or marital satisfaction (Wink and Helson 1997).

It is conceivable that the contradictory empirical findings are due to the different measures of wisdom and subjective well-being as studies vary widely in the operationalization of these elusive constructs. Another possibility is that wisdom is more strongly related to subjective well-being among socially and economically disadvantaged respondents, such as women, minorities, elders, and individuals with a lower educational background, who have fewer resources to find fulfillment, satisfaction, and happiness in the external environment. For example, it is noteworthy that only the two studies with highly educated middle-aged and older adult samples did not find a significant association between measures of wisdom and satisfaction (Brugman 2000; Wink and Helson 1997). Wisdom might be unrelated to well-being and happiness if external life qualities, life chances, and life results are optimal (see Table 1), but it might be necessary for greater well-being and happiness if external life qualities are problematic and economic and physical resources are not available or are declining (Ardelt 2000; Clayton 1982; Kekes 1995). It is easier to be happy when everything goes well than when life is hard. In difficult circumstances, better coping skills and wisdom might be needed to remain happy.

\section{The Present Study}

The present study seeks to explore the association between wisdom and feelings of hedonic happiness, using a Dutch internet sample, by testing the following hypotheses.

Hypothesis 1 Wisdom and happiness are moderately positively related, even after controlling for sex, age, and educational attainment.

Wise people know how to cope with the pains in life and enjoy its pleasures, although they might be more aware of life's negative aspects through their ability to see through illusions (McKee and Barber 1999; Staudinger et al. 2005). Yet, it was not expected that high wisdom scorers were less happy than those with lower wisdom scores. To test for this possibility, we analyzed whether the association between wisdom and happiness was curvilinear.

Hypothesis 2 If wisdom is more important for happiness in difficult circumstances, the correlation between wisdom and happiness will be stronger for women than men, older adults than younger and middle-aged adults, and individuals with lower rather than greater educational attainment. 


\section{Method}

\subsection{Procedure}

On January 31, 2009, De Volkskrant, a national newspaper in The Netherlands, published several opinion pieces on wisdom and offered their readers the opportunity to take an online 'wisdom test.' At the website, readers had the option to fill out a standardized on-line survey consisting of the 39 items of the Three-Dimensional Wisdom Scale (Ardelt 2003). After responding to the items, they were asked whether they wanted to receive feedback on their 'wisdom score' immediately or were willing to participate in a study and answer five additional questions about their age, gender, education, and happiness. Readers either clicked on a button labeled 'Yes, include my answers in the study' or 'No, do not include my answers in the study.' If they clicked on the 'Yes' button, they were asked about their age, gender, level of education, and their current and past happiness. After submitting those answers, participants received their average scores for the cognitive, reflective, and compassionate dimensions of wisdom and their overall wisdom score. If readers clicked on the 'No' button instead, they received their average wisdom scores immediately. General interpretations of scores below the midpoint of the 1-5 scales (a score of $<3$ ), slightly above the midpoint (a score between 3 and $<4$ ), and in the top of the scale (a score between 4 and 5) were provided by De Volkskrant.

\subsection{Measures}

\subsubsection{Happiness}

Happiness was measured by two single questions ('How happy do you feel today?' and 'All considering, how happy have you felt in the last 3 months?') on a scale ranging from 0 (very unhappy) to 9 (very happy). The correlation between the two items was .58 $(p<.001)$. Single item happiness measures have been shown to have good concurrent and convergent validity and seem to be reliable, valid, and viable in community surveys (Abdel-Khalek 2006).

\subsubsection{Wisdom}

Wisdom was assessed by the cognitive, reflective, and compassionate dimensions of the 3D-WS (see Table 2). The 14 items of the cognitive dimension were all worded negatively, measuring an inability or unwillingness to understand a situation or phenomenon thoroughly (e.g., 'Ignorance is bliss'), a tendency to see the world as either black or white (e.g., 'People are either good or bad'), an unawareness of ambiguity and uncertainty in life (e.g., 'There is only one right way to do anything'), and an inability to make important decision despite life's unpredictability and uncertainties ('I am hesitant about making important decisions after thinking about them'). The 12 items of the reflective wisdom dimension assessed the ability and willingness to look at phenomena and events from different perspectives (e.g., 'I always try to look at all sides of a problem') and the absence of subjectivity and projections (e.g., 'Things often go wrong for me by no fault of my own'reversed). The 13 items of the compassionate wisdom dimension gauged the presence of positive, caring, and nurturant emotions and behavior (e.g., 'Sometimes I feel a real compassion for everyone'), including the motivation to foster the well-being of others 
(e.g., 'If I see people in need, I try to help them one way or another'), and the absence of indifferent or negative emotions and behavior toward others (e.g., 'I am annoyed by unhappy people who just feel sorry for themselves'-reversed).

All items were assessed on two 5-point scales, ranging either from 1 ('strongly agree') to 5 ('strongly disagree') or from 1 ('definitely true of myself') to 5 ('not true of myself') and were scored in the direction of higher cognitive, reflective, and compassionate wisdom characteristics before the average of the items was computed separately for the three wisdom dimensions. Cronbach's $\alpha$-values for the cognitive, reflective, and compassionate dimensions of wisdom were $.72, .74$, and .66 , respectively. To obtain a composite wisdom score, the average of the three dimensions was taken. The correlation between the three dimensions ranged from $.48(p<.001)$ to $.53(p<.001)$, resulting in an $\alpha$-value of .75 .

An earlier study with older adults who were unaware that they were completing a wisdom questionnaire showed that the 3D-WS had adequate construct, content, predictive, discriminant, and convergent validity and relatively high 10-month test-retest reliability (Ardelt 2003). The 3D-WS has also successfully been used in samples of adolescents (Bailey and Russell 2008) and young adults from different cultural backgrounds (Ardelt 2010; Benedikovičová and Ardelt 2008; Ferrari et al. 2011) and was significantly correlated $(r=.33)$ with Webster's $(2003,2007)$ Self-Administered Wisdom Scale (SAWS) in an age-diverse internet sample that originated in Australia (Ardelt 2011a; Taylor et al. 2011).

\subsubsection{Demographic Characteristics}

Sex was measured as a dichotomous variable $(0=$ male, $1=$ female $)$. Although it was originally planned to measure age in years, De Volkskrant decided to assess age by seven age categories ranging from 0 (less than 20 years) to 6 (age 70 and above). Educational attainment was gauged by five categories ranging from 0 (elementary education-completed or not) to 4 (higher vocational education or university education).

\subsection{Sample}

The sample included 7037 respondents who completed all of the questions of the on-line survey of De Volkskrant between January 31, 2009 and March, 9, 2009 and gave informed consent for the inclusion of their answers in a research study. Sixty-two percent of the participants were female, and over half (53\%) were between the ages of 40 and 59 years (see Table 3 ). The majority of the respondents $(60 \%)$ had a higher vocational or university education. Hence, the sample was not representative of the Dutch population but was skewed in a middle aged, higher educated direction.

\subsection{Analysis}

Bivariate correlations (Pearson's $r$ ) were performed first to examine whether the three dimensions of wisdom and the demographic variables correlated similarly with the two happiness items to justify averaging the two items into one happiness measure. Due to the large sample size, we chose a stricter significance level of .01 instead of the usual .05 level of significance. A nested multivariate OLS regression analysis was employed to test Hypotheses 1. We analyzed whether the relation between wisdom and happiness was curvilinear by including the square of the wisdom score in the model. Interaction effects 
Table 3 Bivariate correlation matrix between happiness measures, wisdom dimensions, and demographic variables

(1)

(1) How happy do you feel today?

(2) How happy have you felt in the last 3 months?

(3) Cognitive dimension of wisdom

(4) Reflective dimension of wisdom

(5) Affective dimension of wisdom

(6) Sex $(1=$ female $)$

(7) Age less than 20 years

(8) Age 20-29 years

(9) Age 30-39 years

(10) Age 40-49 years

(11) Age 50-59 years

(12) Age 60-69 years

(13) Age 70 years and above

(14) Elementary education (completed or not)

(15) Lower vocational or general intermediate education

(16) Intermediate vocational or general secondary education

(17) Higher general secondary education

(18) Higher vocational education or university

$-$

(2)

(3)

$.58^{* *}$

$.17^{* *} \quad .16^{* *}-$

$.35 * * \quad .38 * * \quad .53 * * \quad$

$.13 * * \quad .10 * * \quad .48 * * \quad .48 * *$

$\begin{array}{lllllll}.01 & -.02 & -.01 & -.03 & .12 * * & .62 & .48\end{array}$

$\begin{array}{lllllll}-.05 * * & -.05 * * & -.09 * * & -.13 * * & -.04 * * & .05 & .23\end{array}$

$\begin{array}{lllllll}-.04 * * & -.00 & .01 & .01 & .02 & .09 & .29\end{array}$

$\begin{array}{lllllll}.00 & .02 & .06 * * & .04 * * & .02 & .14 & .35\end{array}$

$\begin{array}{lllllll}.01 & -.01 & .10 * * & .07 * * & .06 * * & .24 & .43\end{array}$

$\begin{array}{lllllll}.01 & -.02 & .04 * * & .03 * * & .02 & .29 & .45\end{array}$

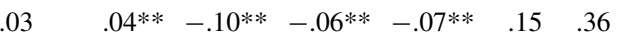

$\begin{array}{lllllll}.02 & .02 & -.13 * * & -.07 * * & -.06 * * & .03 & .18\end{array}$

$\begin{array}{lllllll}-.04 * * & -.04 * * & -.07 * * & -.06 * * & -.01 & .02 & .13\end{array}$

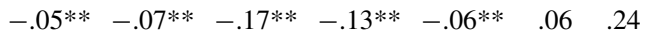

$\begin{array}{llllll}-.05^{* *}-.07 * * & -.17 * * & -.13^{* *}-.06 * * & .19 & .39\end{array}$

$\begin{array}{lllllll}-.01 & .01 & -.04 * * & -.02 & -.03 * * & .13 & .34\end{array}$

$\begin{array}{lllllll}.08 * * & .09 * * & .26 * * & .20 * * & .10 * * & .60 & .49\end{array}$

Listwise deletion of cases, $n=7037$

** $p<0.01$

between wisdom and demographic groups were subsequently added to the model in a forward regression procedure to test whether the association between wisdom and happiness was significantly stronger for relatively disadvantaged sex, age, and educational groups as stated in Hypothesis 2. Wisdom was centered at the mean for the regression analyses to minimize the effects of multicollinearity.

\section{Results}

\subsection{Correlations Between Happiness Measures, Wisdom Dimensions, and Demographic Variables}

As shown in Table 3, the three dimensions of wisdom were positively related to the two happiness items, although the correlations with the reflective dimension of wisdom were stronger than with the cognitive and compassionate wisdom dimensions. A more detailed analysis of the reflective dimension revealed that the presence of self-examination, selfawareness, and self-insight, expressed as an absence of subjectivity and projections, had the strongest correlation with happiness today $(r=0.42, p<.001)$ and happiness in the 
last 3 months ( $r=0.46, p<.001)$, whereas the ability and willingness to look at phenomena and events from different perspectives was more moderately associated with happiness today and in the last 3 months $(r=0.16, p<.001$ with each happiness item; not shown in table). All of the variables were similarly correlated with the two happiness items and the three dimension of wisdom, which justified averaging the two happiness items into one happiness measure and the three wisdom dimensions into one composite wisdom score.

Gender was unrelated to the happiness items. The association between age and happiness appeared to be slightly curvilinear with respondents under age 30 being less happy than other age groups. The correlation between educational attainment and happiness, by contrast, was positive and more linear.

Women tended to score higher on the compassionate wisdom dimension than men did. Respondents younger than age 20 and older than age 59 tended to score lower on the three dimensions of wisdom, whereas respondents between the ages of 30 and 59 tended to score higher on the three wisdom dimensions. All those correlations, however, were relatively weak, except for a somewhat stronger positive association between a higher vocational or university education and the cognitive and reflective dimensions of wisdom, partially supporting prior research (Ardelt 2010).

\subsection{Predictors of Happiness}

A nested multivariate regression analysis was conducted to test the two hypotheses. Based on the bivariate correlation analyses in Table 3, the average of the two happiness items was computed to obtain a single happiness measure as the dependent variable and the three dimensions of wisdom were averaged to construct a composite wisdom score. In Model 2, sex, age, and educational categories were entered separately into the regression equation with the youngest age category (age less than 20 years) and the highest education (higher vocational or university education) as the omitted categories. Model 3 tested for the presence of interaction effects between wisdom and the individual sex, age, and educational categories in a forward regression procedure to minimize problems with multicollinearity.

As predicted in Hypothesis 1, the bivariate correlation between the composite wisdom and happiness scales was significant $(r=0.30, p<.001)$. However, as shown in Model 1 in Table 4 , the association between wisdom and happiness was curvilinear. Figure 1 compares the bivariate association between wisdom and happiness with the quadratic relation shown in Model 1, displayed for the original 1-5 wisdom scale. The quadratic relation suggests that compared to a linear association between wisdom and happiness, respondents at the lower end of the wisdom scale tended to report less happiness, whereas the predicted incremental gain in happiness declined at the higher end of the wisdom scale. Yet, happiness was not expected to decrease at higher levels of wisdom as the turning point of the quadratic function (at 6.13) lies beyond the scale end point for wisdom.

Wisdom explained $9.2 \%$ of the variation in happiness and was a stronger predictor of happiness than any of the demographic variables in Model 2, which together explained another $1 \%$ of its variation. Older adults above the age of 59 tended to be significantly happier than respondents under the age of 20 , and respondents with a lower vocational or general intermediate education tended to be somewhat less happy than those with a higher vocational or university education, although the effects of age and education were modest. Men and women appeared to be equally happy. 
Table 4 Effects of wisdom and demographic characteristics on happiness; nested multivariate regression analysis

\begin{tabular}{|c|c|c|c|c|c|c|c|c|}
\hline \multirow[t]{2}{*}{ Independent variables } & \multicolumn{2}{|c|}{ Model $1 n=7037$} & \multicolumn{2}{|c|}{ Model $2 n=7037$} & \multicolumn{2}{|c|}{ Model $3 n=7037$} & \multicolumn{2}{|c|}{ Model $4 n=5994$} \\
\hline & $\mathrm{b}$ & $\beta$ & $\mathrm{b}$ & $\beta$ & $\mathrm{b}$ & $\beta$ & $\mathrm{b}$ & $\beta$ \\
\hline Wisdom (mean centered) & .93 & $.30 * * *$ & .94 & $.30 * * *$ & .98 & $.32 * * *$ & .94 & $.31 * * *$ \\
\hline Wisdom squared & -.19 & $-.04 * *$ & -.18 & $-.03 * *$ & -.20 & $-.04 * *$ & -.20 & $-.04 * *$ \\
\hline \multicolumn{9}{|l|}{ Demographic controls } \\
\hline Sex $(1=$ female $)$ & & & -.01 & -.00 & -.01 & -.00 & -.01 & -.00 \\
\hline Age less than 20 & & & \multicolumn{2}{|c|}{ Reference } & \multicolumn{2}{|c|}{ Reference } & \multicolumn{2}{|c|}{ Not included } \\
\hline Age $20-29$ years & & & -.03 & -.01 & -.02 & -.01 & \multicolumn{2}{|c|}{ Not included } \\
\hline Age 30-39 years & & & .05 & .02 & .05 & .02 & \multicolumn{2}{|c|}{ Reference } \\
\hline Age $40-49$ years & & & .02 & .01 & .02 & .01 & -.03 & -.01 \\
\hline Age $50-59$ years & & & .04 & .01 & .04 & .02 & -.01 & -.01 \\
\hline Age $60-69$ years & & & .25 & $.08 * * *$ & .26 & $.08 * * *$ & .21 & $.07 * * *$ \\
\hline Age 70 years and above & & & .42 & $.07 * * *$ & .42 & $.07 * * *$ & .37 & $.06 * * *$ \\
\hline Elementary education & & & -.23 & -.03 & -.22 & -.02 & .13 & .01 \\
\hline Lower/intermediate & & & -.16 & $-.03 * *$ & -.14 & -.03 & -.12 & -.03 \\
\hline Intermediate/secondary & & & -.07 & -.03 & -.06 & -.02 & -.07 & -.03 \\
\hline Higher secondary educ. & & & .00 & .00 & -.01 & -.00 & -.01 & -.00 \\
\hline Higher education & & & \multicolumn{2}{|c|}{ Reference } & \multicolumn{2}{|c|}{ Reference } & \multicolumn{2}{|c|}{ Reference } \\
\hline \multicolumn{9}{|l|}{ Interaction effects } \\
\hline Wisdom*higher sec & & & & & -.36 & $-.04 * *$ & & \\
\hline Wisdom*elementary & & & & & & & 1.03 & $.05 * * *$ \\
\hline $\mathrm{R}^{2}$ & & .092 & & .102 & & .104 & & .106 \\
\hline $\mathrm{R}^{2}$ change & & - & & $01 * * *$ & & $001 * *$ & & - \\
\hline
\end{tabular}

$* * p<0.01, * * * p<0.001$

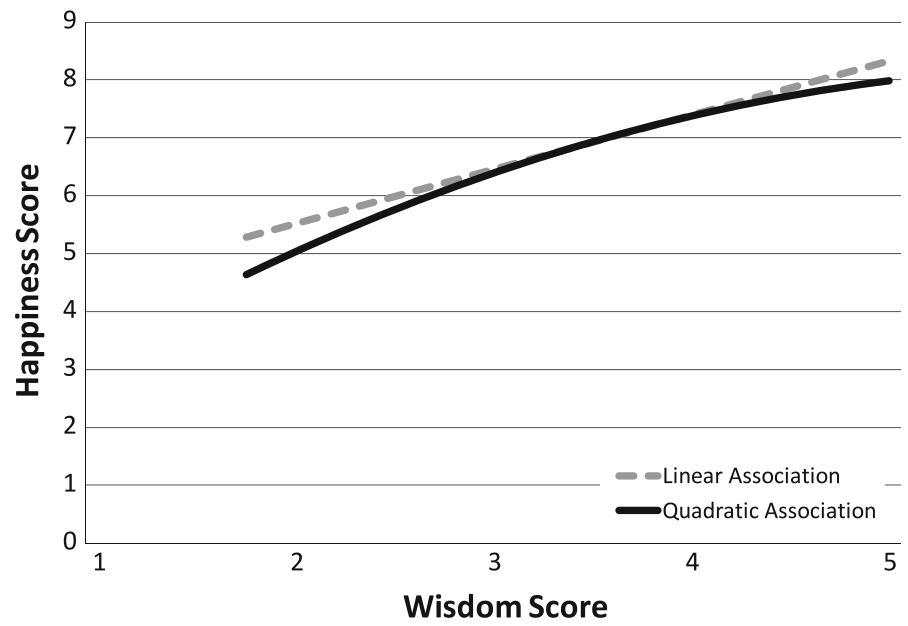

Fig. 1 Linear and quadratic association between self-reported wisdom and happiness 
We used a forward regression procedure to test whether any of the interaction effects between wisdom and the sex, age, and educational groups were significant as expected in Hypothesis 2. As shown in Model 3 in Table 4, only the interaction effect with higher general secondary education was statistically significant, indicating that the relation between wisdom and happiness was significantly smaller for respondents with a higher general secondary education than those with a higher vocational or university education, rejecting Hypothesis 2.

Because respondents in the two youngest age groups might still be in educational training and, therefore, their final educational attainment status is unknown, the analysis was repeated without respondents under the age of 30. As Model 4 in Table 4 shows, the interaction effect between wisdom and elementary education was positive and statistically significant. This means that the relation between wisdom and happiness was significantly stronger for respondents with only an elementary education than those with a higher vocational or university education, supporting Hypothesis 2 for respondents age 30 and older.

\section{Discussion}

The results of this Dutch internet study revealed that wisdom, measured as a combination of self-reported cognitive, reflective, and compassionate personality characteristics, was positively and moderately related to self-reported happiness, even after controlling for sex, age, and education, confirming Hypothesis 1 . The quadratic relation between wisdom and happiness signifies that happiness gains with greater wisdom tended to be lower among high wisdom scorers than among lower wisdom scorers as wise persons might focus more on eudaimonic well-being rather than hedonic happiness (Mickler and Staudinger 2008; Staudinger and Glück 2011). Yet, the quadratic association also suggests that relatively low wisdom affects hedonic happiness more than high levels of wisdom, indicating that a lack of wisdom might indeed be detrimental to happiness.

Hypothesis 2 was rejected. Wisdom was not more strongly related to happiness for women than men and older adults than younger and middle-aged adults. This suggests that wisdom is equally beneficial for men and women and individuals at all stages of the life course. Yet, being female or old by itself is probably not a good indicator for difficult life circumstances. To test the hypothesis that wisdom is most beneficial for subjective wellbeing for individuals in adverse circumstances, more specific information about the respondents' economic, social, and physical resources would be needed. However, it should be noted that among the small group of respondents over the age of 29 with only an elementary education, wisdom did have a significantly stronger association with happiness than among those with a higher vocational or university education, as stated in Hypothesis 2. Wisdom might have a greater impact on happiness when external life qualities and life chances are not optimal by facilitating coping with obstacles and hardships and enabling an appreciation of the good things in life (Ardelt 2000, 2005; Clayton 1982; Kekes 1995).

Among the demographic characteristics, only the two oldest age groups (age 60 and above) were consistently positively related to happiness compared to the youngest age group after controlling for wisdom and the other demographic variables in the models. This positive effect of the oldest age groups on happiness illustrates the well-known paradox of aging (Ryan and Deci 2001) that happiness tends to increase with advancing age despite age-related challenges and losses (Carstensen 1998; Mroczek and Kolarz 1998). 
Our results show that hedonic happiness and wisdom are not as incompatible as some philosophers have stated. This means that a classical objection to the utilitarian ideal of the greatest happiness for the greatest number of people has been empirically refuted. There is no reason to expect that a pig rolling around in the mud would be happier than a Socrates who reflects on the reality of life, as John Stuart Mill already argued (1990 [1863], p. 332). Or as Jahoda (1958) remarked, the view that reality is hostile to individuals is unqualified. Our result lends support to Bentham's (1789 [1970]) philosophy and the work of modern scholars such as Layard (2005) and Kahneman et al. (1997).

Still, our results also highlight that the overlap between wisdom and happiness is small. In our study, wisdom explained only about $9 \%$ of the variation in happiness in the combined sample, and sex, age, and educational attainment explained an additional $1 \%$. This indicates that other factors besides wisdom contribute to happiness (Ryan and Deci 2001). Or, to put it more philosophically, although Sophocles' dictum that 'wisdom is the supreme part of happiness' (quoted in Csikszentmihalyi and Rathunde 1990, p. 36) might be true for wise people, wisdom is clearly not the only source of hedonic happiness.

Alternative explanations for the correlation between wisdom and happiness could be addressed in future studies. Perhaps aspects of personality that influence happiness, also contribute to acquiring wisdom. For example, Neff et al. (2007) found that curiosity was positively correlated with both happiness and the cognitive, reflective, and compassionate dimensions of wisdom. It is therefore possible that personality factors explain the positive correlation between wisdom and happiness.

One major limitation of the study is the on-line convenience sample that was not representative of the general Dutch population. Women, middle-aged adults, and people of higher educational attainment were overrepresented, which might have influenced the results, although we controlled for those demographic characteristics in the analyses. Our sample was also selective among higher age groups. Older adults who use the internet might be more educated, economically privileged, healthier, and/or resourceful than those who do not, which might explain the lack of a significant interaction effect between the older adult age groups and wisdom on happiness. It is still possible that older adults in general and particularly disadvantaged older adults benefit more from wisdom than younger individuals. Another limitation is that respondents knew they were completing a wisdom and happiness questionnaire, which might have biased their answers in a more socially desirable and 'wise' direction. Results might have been different if a performancebased wisdom measure that was unaffected by social desirability bias and inaccurate selfjudgements had been used (Staudinger and Glück 2011). Moreover, the wisdom test was probably an important reason why many participants visited the website of the newspaper in the first place. As a consequence, people with more than an average interest in wisdom were probably overrepresented in the sample, which might have further biased the findings. It is possible that the correlation between wisdom and happiness would have been stronger in a more diverse sample and if respondents had been unaware of the purpose of the study, which might have increased the variability of the wisdom and happiness scores. A common method bias might have also affected the results, although we tried to minimize the effect of common method variance by guaranteeing anonymity, presenting the wisdom questionnaire first and the happiness questions last, and using different answer scales for the wisdom questionnaire and the happiness questions (Podsakoff et al. 2003).

Finally, the cross-sectional nature of the data does not allow us to determine the causality of the relation between wisdom and happiness, although we suspect that the causality is bidirectional. Wisdom probably has a modest positive influence on hedonic happiness by helping people to reflect on their circumstances to cope better with life's hardships (Ardelt 
2005). Furthermore, the development of wisdom by itself might be rewarding and joyful through the experience of self-transcendence (Csikszentmihalyi and Nakamura 2005). But happiness might also foster wisdom. Positive affect and subjective well-being might facilitate self-reflection and a desire to explore the world which, in turn, might stimulate the development of wisdom (Cacioppo and Gardner 1999; Fredrickson and Branigan 2005; Mickler and Staudinger 2008). It is likely that the pursuit of wisdom and happiness reciprocally facilitate each other but are still largely independent processes. Future longitudinal research will need to examine the relative contributions of wisdom and other variables to the attainment of happiness and whether it is more likely that wisdom increases happiness or happiness increases future wisdom.

Open Access This article is distributed under the terms of the Creative Commons Attribution Noncommercial License which permits any noncommercial use, distribution, and reproduction in any medium, provided the original author(s) and source are credited.

\section{References}

Abdel-Khalek, A. M. (2006). Measuring happiness with a single-item scale. Social Behavior and Personality, 34(2), 139-150. doi:10.2224/sbp.2006.34.2.139.

Achenbaum, A. W., \& Orwoll, L. (1991). Becoming wise: A psycho-gerontological interpretation of the Book of Job. International Journal of Aging and Human Development, 32(1), 21-39.

Amir, L. B. (2004). Three questionable assumptions of philosophical counseling. International Journal of Philosophical Practice, 2(1), 9-18.

Aquinas, T. (1923). Summa contra gentiles. London: Burns Oates \& Washbourne Ltd.

Ardelt, M. (1997). Wisdom and life satisfaction in old age. Journal of Gerontology: Psychological Sciences, $52 B(1)$, P15-P27.

Ardelt, M. (1998). Social crisis and individual growth: The long-term effects of the Great Depression. Journal of Aging Studies, 12(3), 291-314.

Ardelt, M. (2000). Intellectual versus wisdom-related knowledge: The case for a different kind of learning in the later years of life. Educational Gerontology: An International Journal of Research and Practice, 26(8), 771-789.

Ardelt, M. (2003). Empirical assessment of a three-dimensional wisdom scale. Research on Aging, 25(3), 275-324.

Ardelt, M. (2004). Wisdom as expert knowledge system: A critical review of a contemporary operationalization of an ancient concept. Human Development, 47(5), 257-285.

Ardelt, M. (2005). How wise people cope with crises and obstacles in life. ReVision: A Journal of Consciousness and Transformation, 28(1), 7-19.

Ardelt, M. (2010). Are older adults wiser than college students? A comparison of two age cohorts. Journal of Adult Development, 17(4), 193-207. doi:10.1007/s10804-009-9088-5.

Ardelt, M. (2011a). The measurement of wisdom: A commentary on Taylor, Bates, and Webster's comparison of the SAWS and 3D-WS. Experimental Aging Research, 37(2), 241-255. doi: 10.1080/0361073X.2011.554509.

Ardelt, M. (2011b). Wisdom, age, and well-being. In K. W. Schaie \& S. L. Willis (Eds.), Handbook of the psychology of aging (7th ed., pp. 279-291). Amsterdam, The Netherlands: Elsevier.

Ardelt, M., Landes, S. D., \& Vaillant, G. E. (2010). The long-term effects of World War II combat exposure on later life well-being moderated by generativity. Research in Human Development, 7(3), 202-220. doi:10.1080/15427609.2010.504505.

Ardelt, M., \& Oh, H. (2010). Wisdom: Definition, assessment, and its relation to successful cognitive and emotional aging. In D. Jeste \& C. Depp (Eds.), Successful cognitive and emotional aging (pp. 87-113). Washington, DC: American Psychiatric Publishing.

Aristoteles (350 B.C.E.). Nicomachean ethics (D. C. Stevenson, Ed., W. D. Ross, Trans.) The Internet classics archive. Web Atomics. Retrieved from http://classics.mit.edu/Aristotle/nicomachaen.html.

Averill, J. R., \& More, T. A. (1993). Happiness. In M. Lewis \& J. M. Haviland (Eds.), Handbook of emotions (pp. 617-629). New York, NY: Guilford Press.

Bailey, A., \& Russell, K. C. (2008). Psycho-social benefits of a service-learning experience. Journal of Unconventional Parks, Tourism \& Recreation Research, 1(1), 9-16. 
Baltes, P. B., \& Staudinger, U. M. (2000). Wisdom: A metaheuristic (pragmatic) to orchestrate mind and virtue toward excellence. American Psychologist, 55(1), 122-136.

Baltes, P. B., Staudinger, U. M., Maercker, A., \& Smith, J. (1995). People nominated as wise: A comparative study of wisdom-related knowledge. Psychology and Aging, 10(2), 155-166.

Barbieri, P. (1997). Habitual desires: The destructive nature of expressing your anger. International Journal of Reality Therapy, 17(1), 17-23.

Beaumont, S. L. (2009). Identity processing and personal wisdom: An information-oriented identity style predicts self-actualization and self-transcendence. Identity: An International Journal of Theory and Research, 9(2), 95-115. doi:10.1080/15283480802669101.

Benedikovičová, J., \& Ardelt, M. (2008). The Three-Dimensional Wisdom Scale in cross-cultural context: A comparison between American and Slovak college students. Studia Psychologica, 50(2), 179-190.

Ben-Shahar, T. (2007). Happier: Learn the secrets to daily joy and lasting fulfillment. New York, NY: McGraw-Hill.

Bentham, J. (1789 [1970]). An introduction to the principles and morals of legislation. London: Athlone Press.

Bergsma, A. (2000). Transhumanism and the wisdom of old genes: Is neurotechnology a source of future happiness? Journal of Happiness Studies, 1(3), 401-417. doi:10.1023/a:1010016532529.

Bianchi, E. C. (1994). Elder wisdom. Crafting your own elderhood. New York: Crossroad.

Brugman, G. M. (2000). Wisdom: Source of narrative coherence and eudaimonia. Delft, The Netherlands: Eburon.

Buss, S. (2004). The irrationality of unhappiness and the paradox of despair. The Journal of Philosophy, 101(4), 167-196.

Cacioppo, J. T., \& Gardner, W. L. (1999). Emotion. Annual Review of Psychology, 50, 191-214. doi: 10.1146/annurev.psych.50.1.191.

Carstensen, L. L. (1998). A life-span approach to social motivation. In J. Heckhausen \& C. S. Dweck (Eds.), Motivation and self-regulation across the life span (pp. 341-364). New York, NY: Cambridge University Press.

Clayton, V. P. (1982). Wisdom and intelligence: The nature and function of knowledge in the later years. International Journal of Aging and Development, 15(4), 315-323.

Clayton, V. P., \& Birren, J. E. (1980). The development of wisdom across the life-span: A reexamination of an ancient topic. In P. B. Baltes \& O. G. Brim Jr (Eds.), Life-span development and behavior (Vol. 3, pp. 103-135). New York: Academic Press.

Collijn, D. (1991). Depressie, zelfschemata en realisme [Depression, self-schemata and realism]. Utrecht: ISOR.

Csikszentmihalyi, M., \& Nakamura, J. (2005). The role of emotions in the development of wisdom. In R. J. Sternberg \& J. Jordan (Eds.), A handbook of wisdom. Psychological perspectives (pp. 220-242). New York: Cambridge University Press.

Csikszentmihalyi, M., \& Rathunde, K. (1990). The psychology of wisdom: An evolutionary interpretation. In R. J. Sternberg (Ed.), Wisdom: Its nature, origins, and development (pp. 25-51). New York: Cambridge University Press.

Ehrenreich, B. (2009). Bright-sided: How the relentless promotion of positive thinking has undermined America (1st ed.). New York: Metropolitan Books.

Erikson, E. H. (1982). The life cycle completed. A review. New York: Norton.

Farb, N. A. S., Anderson, A. K., Mayberg, H., Bean, J., McKeon, D., \& Segal, Z. V. (2010). Minding one's emotions: Mindfulness training alters the neural expression of sadness. Emotion, 10(1), 25-33. doi: 10.1037/a0017151.

Feldman, F. (2008). Whole life satisfaction concepts of happiness. Theoria, 74(3), 219-238. doi: 10.1111/j.1755-2567.2008.00019.x.

Ferrari, M., Kahn, A., Benayon, M., \& Nero, J. (2011). Phronesis, sophia, and hochma: Developing wisdom in Islam and Judaism. Research in Human Development, 8(2), 128-148. doi:10.1080/ 15427609.2011 .568869 .

Fisher, B. J. (1992). Successful aging and life satisfaction: A pilot study for conceptual clarification. Journal of Aging Studies, 6(2), 191-202.

Franklin, S. S. (2010). The psychology of happiness: A good human life. New York, NY: Cambridge University Press.

Fredrickson, B. L., \& Branigan, C. (2005). Positive emotions broaden the scope of attention and thoughtaction repertoires. Cognition and Emotion, 19(3), 313-332. doi:10.1080/02699930441000238.

George, L. K., \& Bearon, L. B. (1980). Quality of life in older persons. Meaning and measurement. New York: Human Sciences Press.

Gerson, E. M. (1976). On "quality of life". American Sociological Review, 41(5), 793-806. 
Haan, N. (1969). A tripartite model of ego functioning: Values and clinical research applications. Journal of Nervous and Mental Diseases, 148(1), 14-30.

Headey, B., \& Wearing, A. (1992). Understanding happiness: A theory of subjective well-being. Melbourne: Longman Cheshire.

Jahoda, M. (1958). Current concepts of positive mental health. New York: Basic Books.

Jason, L. A., Reichler, A., King, C., Madsen, D., Camacho, J., \& Marchese, W. (2001). The measurement of wisdom: A preliminary effort. Journal of Community Psychology, 29(5), 585-598.

Kabat-Zinn, J. (2003). Mindfulness-based interventions in context: Past, present, and future. Clinical Psychology: Science and Practice, 10(2), 144-156. doi:10.1093/clipsy/bpg016.

Kahneman, D., Wakker, P. P., \& Sarin, R. (1997). Back to Bentham?-Explorations of experienced utility. Quarterly Journal of Economics, 112(2), 375-405.

Kekes, J. (1983). Wisdom. American Philosophical Quarterly, 20(3), 277-286.

Kekes, J. (1995). Moral wisdom and good lives. Ithaca, NY: Cornell University Press.

Kramer, D. A. (1990). Conceptualizing wisdom: The primacy of affect-cognition relations. In R. J. Sternberg (Ed.), Wisdom: Its nature, origins, and development (pp. 279-313). New York: Cambridge University Press.

Kramer, D. A. (2000). Wisdom as a classical source of human strength: Conceptualization and empirical inquiry. Journal of Social and Clinical Psychology, 19(1), 83-101.

Kunzmann, U. (2004). Approaches to a good life: The emotional-motivational side to wisdom. In P. A. Linley \& S. Joseph (Eds.), Positive psychology in practice (pp. 504-517). Hoboken, NJ: Wiley.

Kunzmann, U., \& Baltes, P. B. (2003). Wisdom-related knowledge: Affective, motivational, and interpersonal correlates. Personality and Social Psychology Bulletin, 29(9), 1104-1119.

Kupperman, J. J. (2005). Morality, ethics, and wisdom. In R. J. Sternberg \& J. Jordan (Eds.), A handbook of wisdom. Psychological perspectives (pp. 245-271). New York: Cambridge University Press.

Layard, R. (2005). Happiness: Lessons from a new science. New York, NY: Penguin.

Le, T. N. (2011). Life satisfaction, openness value, self-transcendence, and wisdom. Journal of Happiness Studies, 12, 171-182. doi:10.1007/s10902-010-9182-1.

Levenson, M. R., Jennings, P. A., Aldwin, C. M., \& Shiraishi, R. W. (2005). Self-transcendence: Conceptualization and measurement. International Journal of Aging and Human Development, 60(2), 127-143.

Levitt, H. M. (1999). The development of wisdom: An analysis of Tibetan Buddhist experience. Journal of Humanistic Psychology, 39(2), 86-105.

Lyubomirsky, S., \& Lepper, H. S. (1999). A measure of subjective happiness: Preliminary reliability and construct validation. Social Indicators Research, 46(2), 137-155. doi:10.1023/a:1006824100041.

Manheimer, R. J. (1992). Wisdom and method: Philosophical contributions to gerontology. In T. R. Cole, D. D. Van Tassel, \& R. Kastenbaum (Eds.), Handbook of the humanities and aging (pp. 426-440). New York: Springer.

Marinoff, L. (2003). The big questions: How philosophy can change your life. New York, NY: Bloomsbury.

McKee, P., \& Barber, C. (1999). On defining wisdom. International Journal of Aging and Human Development, 49(2), 149-164.

Meeks, T. W., \& Jeste, D. V. (2009). Neurobiology of wisdom: A literature overview. Archives of General Psychiatry, 66(4), 355-365.

Mickler, C., \& Staudinger, U. M. (2008). Personal wisdom: Validation and age-related differences of a performance measure. Psychology and Aging, 23(4), 787-799. doi:10.1037/a0013928.

Mill, J. S. (1990 [1863]). Utilitarianism. Glasgow: Fontana Press.

Mohr, R. D. (1992). Gay ideas: Outing and other controversies. Boston, MA: Beacon Press.

Mroczek, D. K., \& Kolarz, C. M. (1998). The effect of age on positive and negative affect: A developmental perspective on happiness. Journal of Personality and Social Psychology, 75(5), 1333-1349. doi: 10.1037/0022-3514.75.5.1333.

Neff, K. D., Rude, S. S., \& Kirkpatrick, K. L. (2007). An examination of self-compassion in relation to positive psychological functioning and personality traits. Journal of Research in Personality, 41(4), 908-916. doi:10.1016/j.jrp.2006.08.002.

Pascual-Leone, J. (2000). Mental attention, consciousness, and the progressive emergence of wisdom. Journal of Adult Development, 7(4), 241-254.

Perry, C. L., Komro, K. A., Jones, R. M., Munson, K., Williams, C. L., \& Jason, L. (2002). The measurement of wisdom and its relationship to adolescent substance use and problem behaviors. Journal of Child \& Adolescent Substance Abuse, 12(1), 45-63.

Podsakoff, P. M., MacKenzie, S. B., Lee, J.-Y., \& Podsakoff, N. P. (2003). Common method biases in behavioral research: A critical review of the literature and recommended remedies. Journal of Applied Psychology, 88(5), 879-903. doi:10.1037/0021-9010.88.5.879. 
Priesner, S. (1999). Gross National Happiness-Bhutan's vision of development and its challenges. In Gross national happiness. Discussion papers (pp. 24-52). Thimphu, Bhutan: The Centre for Bhutan Studies.

Ryan, R. M., \& Deci, E. L. (2001). On happiness and human potentials: A review of research on hedonic and eudaimonic well-being. Annual Review of Psychology, 52, 141-166. doi:10.1146/annurev.psych. 52.1.141.

Ryff, C. D. (1989). Happiness is everything, or is it? Explorations on the meaning of psychological wellbeing. Journal of Personality and Social Psychology, 57(6), 1069-1081.

Ryff, C. D., \& Keyes, C. L. M. (1995). The structure of psychological well-being revisited. Journal of Personality and Social Psychology, 69(4), 719-727.

Speca, M., Carlson, L. E., Goodey, E., \& Angen, M. (2000). A randomized, wait-list controlled clinical trial: The effect of a mindfulness meditation-based stress reduction program on mood and symptoms of stress in cancer outpatients. Psychosomatic Medicine, 62(5), 613-622.

Staudinger, U. M., Dörner, J., \& Mickler, C. (2005). Wisdom and personality. In R. J. Sternberg \& J. Jordan (Eds.), A handbook of wisdom. Psychological perspectives (pp. 191-219). New York: Cambridge University Press.

Staudinger, U. M., \& Glück, J. (2011). Psychological wisdom research: Commonalities and differences in a growing field. Annual Review of Psychology, 62(1), 215-241. doi:10.1146/annurev.psych.121208. 131659.

Staudinger, U. M., \& Kunzmann, U. (2005). Positive adult personality development: Adjustment and/or growth? European Psychologist, 10(4), 320-329.

Sternberg, R. J. (Ed.). (1990). Wisdom: Its nature, origins, and development. New York: Cambridge University Press.

Sternberg, R. J. (1998). A balance theory of wisdom. Review of General Psychology, 2(4), 347-365.

Sternberg, R. J., \& Jordan, J. (Eds.). (2005). A handbook of wisdom. Psychological perspectives. New York: Cambridge University Press.

Takahashi, M., \& Overton, W. F. (2002). Wisdom: A culturally inclusive developmental perspective. International Journal of Behavioral Development, 26(3), 269-277.

Taylor, M., Bates, G., \& Webster, J. D. (2011). Comparing the psychometric properties of two measures of wisdom: Predicting forgiveness and psychological well-being with the Self-Assessed Wisdom Scale (SAWS) and the Three-Dimensional Wisdom Scale (3D-WS). Experimental Aging Research, 37(2), $129-141$.

Vaillant, G. E. (2002). Aging well: Surprising guideposts to a happier life from the landmark Harvard Study of Adult Development. Boston, MA: Little, Brown.

Veenhoven, R. (2004). Happiness as a public policy aim: The greatest happiness principle. In P. A. Linley \& S. Joseph (Eds.), Positive psychology in practice (pp. 658-678). Hoboken, NJ: Wiley.

Waterman, A. S. (1993). Two conceptions of happiness: Contrasts of personal expressiveness (eudaimonia) and hedonic enjoyment. Journal of Personality and Social Psychology, 64(4), 678-691. doi: 10.1037/0022-3514.64.4.678.

Webster, J. D. (2003). An exploratory analysis of a self-assessed wisdom scale. Journal of Adult Development, 10(1), 13-22.

Webster, J. D. (2007). Measuring the character strength of wisdom. International Journal of Aging and Human Development, 65(2), 163-183.

Wink, P., \& Helson, R. (1997). Practical and transcendent wisdom: Their nature and some longitudinal findings. Journal of Adult Development, 4(1), 1-15. 